\title{
Proteomics analysis of colon cancer progression
}

\author{
Saira Saleem ${ }^{1 *} \mathbb{0}$, Sahrish Tariq ${ }^{1}$, Iffat Aleem¹, Sadr-ul Shaheed², Muhammad Tahseen ${ }^{3}$, Aribah Atiq ${ }^{3}$, \\ Sadia Hassan ${ }^{4}$, Muhammad Abu Bakar ${ }^{5}$, Shahid Khattak ${ }^{6}$, Aamir Ali Syed ${ }^{6}$, Asad Hayat Ahmad ${ }^{3}$, \\ Mudassar Hussain ${ }^{3}$, Muhammed Aasim Yusuf ${ }^{7}$ and Chris Sutton ${ }^{2}$
}

\begin{abstract}
Background: The aim of this pilot study was to identify proteins associated with advancement of colon cancer (CC). Methods: A quantitative proteomics approach was used to determine the global changes in the proteome of primary colon cancer from patients with non-cancer normal colon (NC), non-adenomatous colon polyp (NAP), non-metastatic tumor (CC NM) and metastatic tumor (CC M) tissues, to identify up- and down-regulated proteins. Total protein was extracted from each biopsy, trypsin-digested, iTRAQ-labeled and the resulting peptides separated using strong cation exchange (SCX) and reverse-phase (RP) chromatography on-line to electrospray ionization mass spectrometry (ESI-MS).

Results: Database searching of the MS/MS data resulted in the identification of 2777 proteins which were clustered into groups associated with disease progression. Proteins which were changed in all disease stages including benign, and hence indicative of the earliest molecular perturbations, were strongly associated with spliceosomal activity, cell cycle division, and stromal and cytoskeleton disruption reflecting increased proliferation and expansion into the surrounding healthy tissue. Those proteins changed in cancer stages but not in benign, were linked to inflammation/ immune response, loss of cell adhesion, mitochondrial function and autophagy, demonstrating early evidence of cells within the nutrient-poor solid mass either undergoing cell death or adjusting for survival. Caveolin-1, which decreased and Matrix metalloproteinase-9, which increased through the three disease stages compared to normal tissue, was selected to validate the proteomics results, but significant patient-to-patient variation obfuscated interpretation so corroborated the contradictory observations made by others.
\end{abstract}

Conclusion: Nevertheless, the study has provided significant insights into CC stage progression for further investigation.

Keywords: Colon cancer, iTRAQ proteomics, Orbitrap fusion, Biomarkers

\section{Introduction}

Colorectal cancers (CRC) are the 3rd most common malignancies in the world. The global burden of CRC is expected to be more than 2.2 million new cases and 1.1 million deaths by 2030 [1]. In Asia, choice of unhealthy

\footnotetext{
*Correspondence: sairas@skm.org.pk

${ }^{1}$ Basic Science Research, Shaukat Khanum Memorial Cancer Hospital and Research Centre, 7-A Block R-3, Johar Town, Lahore 54000, Pakistan Full list of author information is available at the end of the article
}

diet leading to obesity and metabolic syndrome, lack of public awareness on first choice of screening tests, poor public education for prevention, limited resources and support of healthcare authorities is resulting in increased susceptibility to CRC [2]. A positive relationship of family history, high fat diet, smoking and constipation exists among patients with a mean age of $41.47 \pm 15.47$ [3]. A cohort of 33 studies on over half a million subjects in the Asia-Pacific region concluded that other than body mass index and lack of physical activity $(\mathrm{p}<0.05)$, height 
was strongly associated with CRC mortality such that an extra $5 \mathrm{~cm}$ in height was associated with $10 \%$ (95\% confidence interval) additional risk, after adjustment for other factors. Diabetes and smoking increased the risk by $26 \%$ and $43 \%$, respectively, while alcohol consumption, waist circumference and fasting blood glucose were not associated with CRC mortality [4].

Pakistan is situated in Southern Asia with distinct Punjabi, Sindhi, Pashtun, Baloch and Muhajir ethnic groups. The incidence of CRC is similar to developed Asian countries such as Japan, Republic of Korea and Singapore, but much lower than in Western developed countries [5]. Unfortunately, due to the absence of a national logging system for incidence, statistics on deaths due to cancers, survival rates cannot be estimated [6]. Information from individual health institutes, however, provides a valuable resource for Karachi, Sind [7], Rawalpindi and Punjab [8]. For example, the Cancer Registry at Shaukat Khanum Memorial Cancer Hospital and Research Centre (SKMCH\&RC) operates to register cancer burden for the province of Punjab, and observed that CRC presents at an advanced stage and at a younger age (mean age 46.5 years) than other countries of similar wealth status [9]. The symptoms of CRC, such as rectal bleeding, persistent change in bowel habits, weight loss and continuous abdominal discomfort are often ignored due to embarrassment, but once addressed in a clinical environment are limited by the availability of doctors $(7.8 / 10,000$ population as per WHO observations) and resources (few screening centres in Punjab for a population of 30 million) to diagnose the disease through endoscopy and polyp histopathology. Consequently, a new front-line screening approach is required that can breakdown the cultural and economic barriers in Pakistan. The development of a biomarker-based diagnostic assay would enable greater acceptance of and accessibility to screening programs for CRC.

Colorectal cancer is a term used for the cancers of colon, rectosigmoid, rectum, anus and anal canal, which share similar histology however, distribution of cells and thickness of smooth muscles varies dependent on their function. Most of the pathology statistics are combined for CRC and do not provide regio-specific data. The colon is primarily responsible for the absorption of water and electrolytes while the rectosigmoid and rectum are for the storage of excreta for a short time. In SKMCH\&RC, a total of 75,657 neoplasms $(48.84 \%$ in males and $51.16 \%$ in females) primarily from Punjab were registered from 1994-2015, of which CRC ranked 5th most common (3530 cases) after breast cancer, leukemia, lip and oral cavity and non-Hodgkin's lymphoma. Of the CRC cases $41.44 \%$ were colon cancers (964 in males and 499 in females), $7.19 \%$ were rectosigmoid (172 in males and 82 in females), rectal cancer $44.36 \%$ (1054 in males and 512 in females) and $6.99 \%$ of anus and anal canal (157 in males and 90 in females) (https://shaukatkhanum. org.pk/) [10].

Proteomics has been used previously to identify biomarkers of colorectal cancer though frequently using in vitro cell line models [11-13]. Those studies using biopsies often pooled samples from a number of patients from various sites (colon, rectum) and disease stages (metastatic and non-metastatic disease) to gain sufficient material for proteomics analysis. To support proteomics research of stage-specific (non-metastatic/node-negative and metastatic/node-positive) and site-specific (colon in our case) pooling of samples for specific protein profile, we pooled only colon tissues from exactly same stage (for non-metastatic colon cancer (CC NM). We pooled samples from patients who had primary disease in colon and were node-negative and for metastatic colon cancer (CC $\mathrm{M})$, samples were pooled from patients who had tumors in colon and other organs (e.g. liver) of the body or were node-positive. Some studies have used matched, macroscopically normal margin around the borders of tumor for comparison of healthy and cancer tissues protein profiles, however, the margin may contain infiltrating tumor cells or cells in transition and therefore not be defined as normal tissue with certainty $[14,15]$. For non-cancer $\mathrm{NC}$, we pooled colon lining tissues from non-cancer screening patients and for the benign, it was made sure that the patient has no malignancy.

One of the most complete studies to-date has been a label-free quantitative proteomics study of 64 colon cancer tissues and 31 rectum cancer tissues identifying 7526 proteins [16]. However, the molecular mechanisms underlying transformation of normal colon mucosa into malignancy and subsequent metastatic dissemination still remain unclear, and would benefit from a proteomics investigation of stage-specific disease development. To address this, and identify biomarkers indicative of disease progression, we performed a two-stage study. (a) iTRAQbased proteomics analysis of disease progression using ethnically-, anatomically- and stage-specific, pooled colon biopsy protein extracts. (b) $\beta$-actin, Matrix metalloproteinase-9 (MMP-9) and caveolin-1 (CAV-1) western blot analysis of individual, stage-specific patient biopsies to compare with the proteomic analysis.

\section{Materials and methods}

\section{Patients and samples}

Ethical approval for this prospective study was obtained from the Institutional Review Board (registered with Office for Human Research Protections [OHRP], USA; IORG0004939) at SKMCH\&RC, Lahore, Pakistan. A total of 98 tissue biopsies were obtained after getting consent 
from patients undergoing screening colonoscopy and/or invasive surgery from 2015-2019. Resected specimens were grossed by a pathologist and preserved either by fixing in formalin for embedding into paraffin wax for histopathological diagnosis or stored fresh at $-80{ }^{\circ} \mathrm{C}$. The presence of cancer cells in the acquired specimen was confirmed independently by two clinical pathologists. For proteomic analysis, fresh frozen samples $(n=12)$ were selected from patients without prior chemotherapy and/or radiation and categorised as non-cancer, normal (NC), non-cancer non-adenomatous polyp (NAP), colon cancer, non-metastatic (CC NM) and colon cancer metastatic (CC M) (Additional file 1: Table S1a). For validation studies of selected targets, biopsies from an additional 86 patients without prior chemotherapy and/or radiation were collected (NC and NAP samples during colonoscopy and CC NM and CC M samples during surgery) for Western blot analysis (Additional file 1: Table S1b).

\section{Protein extraction}

The samples were processed under identical conditions. Tissue biopsies $\left(5 \mathrm{~mm}^{3}\right)$ from minimum of two patients for each type of sample (NC, NAP, CC NM and CC M) were pooled. The protein extraction method was adapted from a previously described dual lysis buffer approach [17]. Each specimen was first homogenized in RIPA lysis solution $(50 \mu \mathrm{L}, \mathrm{PBS} \mathrm{pH} 7.4,0.25 \%$ sodium deoxycholate, $0.1 \%$ SDS containing EDTA-free protease inhibitor cocktail) followed by vortexing for $30 \mathrm{~min}$ at room temperature (RT) and sonicated on ice for $20 \mathrm{~s}$ using a Status US70 sonicating probe (Philips Harris Scientific, Hyde, UK). The samples were then centrifuged at $13,4000 \mathrm{rpm}$ for $20 \mathrm{~min}$ at $4{ }^{\circ} \mathrm{C}$ and liquid phase extracted to new tubes. Urea lysis buffer $(50 \mu \mathrm{L}, 7 \mathrm{M}$ urea, $2 \mathrm{M}$ thiourea, $4 \% \mathrm{w} / \mathrm{v}$ CHAPS, $50 \mathrm{mM}$ DTT containing EDTA-free protease inhibitor cocktail) was added to the residual pellet, vortexed, sonicated and centrifuged as described above. The supernatant was combined with RIPA buffer extract. The urea lysis step was repeated on the residual pellet to extract all proteins giving a total volume of $200 \mu \mathrm{L}$. The protein concentration of samples was determined by Bradford assay (Sigma, Poole, UK). To a $70 \mu \mathrm{g}$ aliquot of each protein extract, $1 \mathrm{~mL}$ of chilled acetone was added and allowed to precipitate overnight at $-20{ }^{\circ} \mathrm{C}$. The precipitated contents were centrifuged at $13,400 \mathrm{rpm}$ for 20 min at $4{ }^{\circ} \mathrm{C}$, the supernatant discarded and the pellet used for proteomics preparation.

\section{Peptide preparation and iTRAQ labelling}

Each protein precipitate $(70 \mu \mathrm{g})$ was re-suspended in $8 \mathrm{M}$ urea, reduced with $50 \mathrm{mM}$ DTT for $20 \mathrm{~min}$ at $60{ }^{\circ} \mathrm{C}$ and then alkylated using $100 \mathrm{mM}$ IAA for $20 \mathrm{~min}$ at RT, in the dark. Each mixture was diluted to reduce the urea concentration and digested with sequence grade trypsin (Roche Diagnostics, Burgess Hill, UK) $(2.5 \mu \mathrm{L}$ of $1 \mathrm{mg} /$ $\mathrm{mL}$ prepared in $2 \mathrm{mM}$ hydrochloric acid) was carried out overnight at $37{ }^{\circ} \mathrm{C}$ using a 1:10 trypsin-to-protein ratio $(1: 10 \mathrm{w} / \mathrm{w})$. After digestion, peptide samples were lyophilized and re-suspended in $10 \mu \mathrm{L}$ of $1 \mathrm{M}$ tetraethylammoniumborohydride (TEAB) containing 0.1\% SDS. Each digest was incubated with an ITRAQ 4-plex reagent (SCIEX UK Limited, Warrington, UK) - NC with iTRAQ 114, NAP with 115, CC NM with 116 and CC M with 117 (Table 1), for $90 \mathrm{~min}$ at RT. HPLC grade water was added to stop the reaction. The labelled peptides were then pooled, desalted on an Isolute $\mathrm{C}_{18} \mathrm{RP}$ column (Kinesis Ltd., St. Neots, UK) and the $80 \% \mathrm{CH}_{3} \mathrm{CN}, 0.05 \%$ TFA eluate lyophilized. The pooled iTRAQ-labelled samples (Table 1) were fractionated on a SCX column (Isolute SPE column, Kinesis Ltd.) using stepwise elution with $0.03,0.06,0.09,0.12,0.15,0.18,0.24,0.3,0.5,0.7$ and $1 \mathrm{M}$ $\mathrm{KCl}$ buffer. The fractions, including flow-through containing non-bound peptides, were desalted through $\mathrm{C}_{18}$ $\mathrm{RP}$ cartridges, lyophilized and stored at $-20{ }^{\circ} \mathrm{C}$.

\section{HPLC-ESI MS/MS}

The SCX fractions were analysed in duplicate on an UltiMate 3000 nano-HPLC-linked to an Orbitrap Fusion mass spectrometer (ThermoFisher, Hemel Hempstead, $\mathrm{UK})$. Lyophilized fractions were resuspended in $0.1 \%$ formic acid (FA), $2 \mu \mathrm{L}$ injected, and washed on a $\mathrm{C}_{18}$, $300 \mu \mathrm{m} \times 5 \mathrm{~mm}, 5 \mu \mathrm{m}$ diameter, $100 \AA$ Pep-Map precolumn (LC Packings, Sunnyvale, CA) before transfer to a $\mathrm{C}_{18}, 75 \mu \mathrm{m} \times 50 \mathrm{~cm}, 2 \mu \mathrm{m}$ diameter, $100 \AA$ PepMap column (LC Packings) and peptides eluted with a linear gradient to $10-30 \%$ mobile phase B ( $80 \%$ acetonitrile, $0.1 \%$ FA) over $90 \mathrm{~min}$, followed by $30-50 \%$ mobile phase B for $15 \mathrm{~min}$. After washing in $90 \%$ solvent B for $10 \mathrm{~min}$, the column was re-equilibrated for $20 \mathrm{~min}$ prior to the next injection. All data was acquired in data-dependent positive polarity mode with a spray voltage of $2200 \mathrm{~V}$ and ion transfer tube temperature of $275{ }^{\circ} \mathrm{C}$. For MS, Orbitrap resolution was set at $120 \mathrm{~K}$ with scan range 350 $1500 \mathrm{~m} / \mathrm{z}$, injection time of $50 \mathrm{~ms}$. MS filter setting for parent ions; charge states from 2 to 7 , dynamic exclusion duration was 70 and intensity threshold 5000. All MS/MS

Table 1 Pooled protein extracts for ITRAQ 4-Plex labelling

\begin{tabular}{lll}
\hline $\begin{array}{l}\text { Pooled tissues } \\
\text { from patients }\end{array}$ & Sample ID & iTRAQ label \\
\hline$n=4$ & Non-cancer normal colon lining (NC) & 114 \\
$n=2$ & Non-adenomatous colon polyp (NAP) & 115 \\
$n=4$ & Colon cancer (non-metastatic) (CC NM) & 117 \\
$n=2$ & Colon cancer (metastatic) (CC M) & 116 \\
\hline
\end{tabular}


data was acquired in the Ion Trap with a quadrupole isolation window 1.2, CID collision energy $35 \%$, with maximum injection time of $50 \mathrm{~ms}$ and AGC target 10,000. iTRAQ quantification was performed through $\mathrm{MS}^{3}$ in the Orbitrap; resolution of $30 \mathrm{~K}$, mass range 110-500, 65\% HCD collision energy and maximum ion injection time was $105 \mathrm{~ms}$.

\section{Database searching}

Proteome Discoverer 2.1 software was used to process Orbitrap Fusion data, with Mascot version 2.4 (Matrix Science, London, UK) search engine against the SwissProt database version 2016 (containing 552,259 human protein sequences). The search parameters used were: trypsin digestion, 2 missed cleavages, variable modification of methionine oxidation, fixed modifications of cysteine (carbamidomethylation) and iTRAQ (lysine and $\mathrm{N}$-termini). A precursor mass tolerance of $10 \mathrm{ppm}$ and fragmentation mass tolerance of $0.6 \mathrm{Da}$ were selected. Non-redundant protein profiles were created by combining the search results from all 2D LC analyses using a confidence interval threshold set to a p-value $<0.05$ (equivalent to a Mascot score of $\geq 22$ ), and filtered to include only Master Protein Candidates with 2 or more PSMs and at least one peptide with Mascot score $\geq 22$ (FDR for peptide and protein searches was $<1 \%$ ). iTRAQ ratios were determined relative to the non-cancer control (NAP/NC - 115/114, CC NM/NC - 116/114, and CC $\mathrm{M} / \mathrm{NC}-117 / 114)$. The median ratio for the total complement of proteins for each comparison was determined, the ratios of the individual proteins normalised, converted to $\log _{2}$. Significantly up-regulated and downregulated proteins for each experimental condition (NAP/NC, NM/NC and M/NC) were defined as those with ratio $> \pm$ standard deviation (SD) of $\log _{2}$ median. Protein-protein interactions analysis was performed using STRING (version 10.0, http://string-db.org/) for appreciably up- or down-regulated protein clusters.

\section{Western blotting}

Protein extracts from individual tissue biopsies were prepared using RIPA lysis buffer as described above [17], $10 \mu \mathrm{g}$ protein of each were analysed individually by SDS-PAGE (Bio-Rad Mini Gel, Hercules, CA) on 10\% polyacrylamide gels and electroblotted to a polyvinyldifluoride (PVDF) membrane (Millipore; Immobilon-FL, 0.45- $\mu \mathrm{m}$ thickness) using a Mini Trans-Blot Electrophoretic Transfer Cell (Bio-Rad) [18]. Blotted membranes were blocked with $5 \%$ skimmed milk solution in $20 \mathrm{mM}$ Tris; pH 7.5, $150 \mathrm{mM} \mathrm{NaCl}, 0.1 \%$ Tween-20 (TBST) for $45 \mathrm{~min}$ at room temperature, incubated with primary antibody [anti-goat human CAV-1 (R\&D Systems, Abingdon, UK, 1:2000 dilution), anti-mouse human MMP-9
(R\&D Systems, Minneapolis, USA, 4:1000 dilution or rabbit anti-human $\beta$-Actin (Abcam, Cambridge, UK, 1:1000 dilution)] overnight at $4{ }^{\circ} \mathrm{C}$ and washed 3 times with TBST. Protein extracted from one biopsy, for which there was an adequate supply, was selected for inclusion on each blot to enable inter-experimental normalization. Blots were incubated with horseradish peroxidase (HRP)conjugated secondary antibody [polyclonal donkey antigoat (R\&D Systems; 1:1000), HRP conjugated polyclonal goat anti-mouse (R\&D Systems; $1: 1000)$ or HRP conjugated polyclonal goat anti-rabbit (Abcam; 1:10,000)], respectively, washed 3 times with TBST and once with TBS (without Tween 20). Proteins were detected using ECL solution (GE Healthcare, Little Chalfont, UK) and chemiluminescent exposures captured on a Syngene (Cambridge, UK) GBOX using default settings.

\section{Results}

The main objective of this study was to look for proteins that play important biological roles in colon carcinogenesis and could be manipulated for their diagnostic value. Cancer patients were recruited based on TNM staging (Stage I, II, III, IV) in order to ascertain protein changes with disease progression (Table 1, Additional file 1: Table S1a). Stage I and II cancers are restricted to the primary site (colon) with no positive nodes and are referred to as non-metastatic (CC NM). In the case of stage III regional lymph nodes showed positivity for the presence of malignant cells confirming the disease spread while stage IV patients show malignant cells in secondary nearby organs as well. Both stage III and stage IV were referred to as metastatic (CC $\mathrm{M}$ ), but all samples were taken from the primary tumors. We were also occasionally able to procure non-cancer normal colon tissues for comparison with matched NAP sample. The non-cancer status of the patients was confirmed by screening colonoscopy, taking a part of normal colon lining followed by its histopathology reports. Non-cancer patients were selected as a control group as there was less likelihood of mutated genes and the functional proteins would represent healthy profiles for comparisons with molecular signatures for cancer tissues. Tissue biopsies $\left(5 \mathrm{~mm}^{3}\right)$ from minimum of two patients for each type of sample (NC, NAP, CC NM and CC M) were pooled, from which an average of $70 \mu \mathrm{g}$ of protein was extracted for proteomics analysis.

A total list of 2777 non-redundant proteins were detected with 2 PSMs, of which 2768 had 2 iTRAQ value (Additional file 2: Table S2), PRoteomics IDEntifications (PRIDE) PXD. Protein iTRAQ ratios were normalized to enable stage-related comparisons (NAP/ $\mathrm{NC}, \mathrm{CC} \mathrm{NM} / \mathrm{NC}$ and $\mathrm{CC} \mathrm{M} / \mathrm{NC}$ ), and significantly up- and down-regulated proteins $\left(+/-1 \log _{2}\right.$ standard 
Table 2 Cluster analysis according to observed response modes of proteins in each of the diseased states relative to normal non-cancer tissue

\begin{tabular}{|c|c|c|c|}
\hline Group & Response & No. of proteins & $\begin{array}{l}\text { PPI } \\
\text { enrichment, } \\
\text { p-value }\end{array}$ \\
\hline 1 & DDD & 142 & $<1.0 \mathrm{e}-16$ \\
\hline 2 & DDU & 36 & $4.88 \mathrm{E}-15$ \\
\hline 3 & DDI & 0 & - \\
\hline 4 & DUD & 25 & $1.32 \mathrm{E}-09$ \\
\hline 5 & DUU & 93 & $1.37 E-06$ \\
\hline 6 & DUI & 5 & 1 \\
\hline 7 & DID & 0 & - \\
\hline 8 & DIU & 0 & - \\
\hline 9 & DII & 2 & 1 \\
\hline 10 & UDD & 198 & $<1.0 \mathrm{e}-16$ \\
\hline 11 & UDU & 56 & $2.81 E-05$ \\
\hline 12 & UUD & 64 & $2.83 E-12$ \\
\hline 13 & UDU & 0 & - \\
\hline 14 & UUU & 1636 & $1.00 \mathrm{E}-16$ \\
\hline 15 & UUI & 78 & $3.86 \mathrm{E}-05$ \\
\hline 16 & UID & 0 & - \\
\hline 17 & UIU & 48 & $4.25 E-09$ \\
\hline 18 & UII & 121 & $<1.0 \mathrm{E}-16$ \\
\hline 19 & IDD & 5 & 1 \\
\hline 20 & IDU & 0 & - \\
\hline 21 & IDI & 0 & - \\
\hline 22 & IUD & 2 & 1 \\
\hline 23 & IUU & 104 & $<1.03-16$ \\
\hline 24 & IUI & 16 & $2.80 E-05$ \\
\hline 25 & $\| \mathrm{D}$ & 0 & - \\
\hline 26 & $\| U$ & 12 & 0.477 \\
\hline 27 & III & 125 & $<1.0 \mathrm{E}-16$ \\
\hline
\end{tabular}

Italic values indicate significance of $p$-values $(p<0.05)$. This means that proteins in the same group have enriched interactions indicating these are partially biologically connected

deviation respectively) were identified (Table 2). Proteins were clustered into 27 groups based in increased (I), unchanged (U) or decreased (D) for each of the three disease stages relative to normal colon, NAP/NC, CC $\mathrm{NM} / \mathrm{NC}$ and CC M/NC. This analysis provided groups of protein associated with disease progression. As would be expected, the largest cluster comprising $59 \%$ of the total protein complement (Fig. 1, Cluster C14, UUU) exhibited no significant change in any of the three disease stages suggesting no roles in oncogenic processes or are modified post-translationally rather than via transcriptional activation / deactivation. Other clusters containing a large complement of proteins were those indicative of disease progression (Fig. 1). For example, 125 proteins were increased in all stages (Cluster 27, III, Fig. 1) relative to the NC control, representing early expression changes in colon cancer initiation and were sustained through to metastatic disease (Fig. 1). Whereas 121 proteins were increased in cancer tissues (CC NM and CC M, Cluster 18, UII, Fig. 1) which were associated with cancer progress and 78 increased only in the metastatic stage which were responsible for later oncogenic events (Cluster 15, UUI, Fig. 1). Encouragingly, the smallest clusters or those with no proteins, were those associated with sporadic responses, for example DDI (Cluster 3, Fig. 1) decreased in NAP and CC NM but increased in CC M). Within the main clusters, many of the proteins that changed in expression demonstrated functional importance, which were analysed by STRING analysis.

\section{Proteins changed in all stages of disease progression (clusters III and DDD)}

There was a significant up-regulation of RNA metabolism and spliceosome-associated protein expression $(\mathrm{p}=6.12 \mathrm{e}-15)$, cell cycle division proteins (cell division cycle 5-like protein, cell division cycle and apoptosis regulator protein 1 , nuclear autoantigenic sperm protein, acidic leucine-rich nuclear phosphoprotein 32 family member $A$ and $B$ ), and chromatin folding/remodeling proteins (high mobility group protein A1, B1, B2 and B3 isoforms and SWI/SNF-related matrix-associated actindependent regulator of chromatin subfamily E member 1) in all stages (III) relative to non-cancer indicative of enhanced replication, transcription and translation leading to cell proliferation in colon cancer stages (Additional file 3: Figure S1(i), Table 3a). Similarly STRING analysis of the proteins decreased in all disease stages (DDD) were very strongly associated with extracellular matrix organization $(\mathrm{p}=8.86 \mathrm{e}-20)$ (Additional file 3: Figure S1(ii), Table 3b). Of particular note, 10 of the 17 collagen isoforms detected were decreased in all stages of colon malignancy and 6 others showing evidence of reduction compared to healthy controls. This represents a distinct difference in normal tissue comprising a high composition of extracellular matrix and stroma compared to tumors where the cellularity is more dense. Elastin and proteoglycans (basement membrane-specific heparan sulfate proteoglycan core protein, bone marrow proteoglycan, chondroitin sulfate proteoglycan 4 and proteoglycan 3), laminin alpha, beta and gamma subunits, decorin, biglycan, basigin and nidogen 1 and 2 also exhibited evidence of reduced levels compared to normal tissue.

The DDD cluster were also associated with cytoskeleton disruption (e.g. tropomyosin alpha-1, tropomyosin beta, tubulin beta-2A, myosin light polypeptide 6 , myosin regulatory light polypeptide 9 , myosin-11, filamin- $\mathrm{C}$, desmin, smoothelin, leiomodin-1 and peripheral plasma membrane protein CASK) correlating 


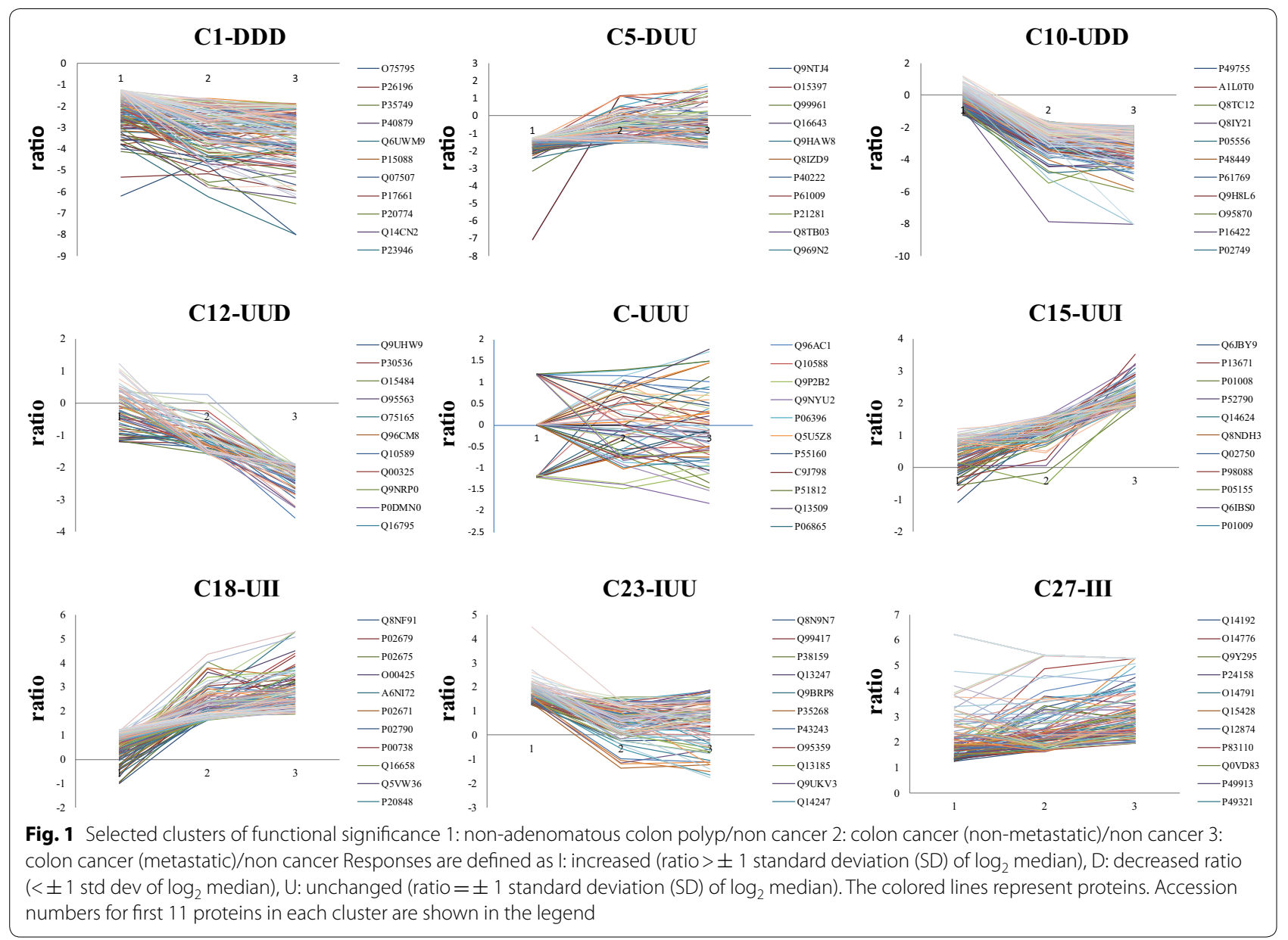

with various structural changes in colon during disease progression, such as loss of cell contour associated with cell transformation and metastasis (Table 3b, Additional file 3: Figure S1(ii)). In addition, proteins responsible for colon mucosal function relating to excretion, transport of metabolites and modification of xenobiotics (UDP-glucuronosyltransferase isoforms 2A3, 2B7, 2B17, liver carboxylesterase 1, sulfate transporter, chloride anion exchanger, calcium-activated chloride channel regulator 4, cleft lip and palate transmembrane protein 1-like protein, canalicular multispecific organic anion transporter 2, ADP-ribosylation factor-like protein 6 -interacting protein 1 , mitochondrial amidoxime reducing component 2 , mitochondrial calcium uniporter protein, plasma membrane calciumtransporting ATPase 1) were decreased, indication that the cells no longer function for their intended purpose in the colon.

An increase in serine proteases HTRA3, myeloblastin and lactotransferrin in all stages and metalloproteinases (MMP-9, ADAMTS4 and neutrophil elastase) in CC NM and CC M, supports degradation of the stroma surrounding the tissues as the tumor progresses. The action of these proteases may inhibit TGF-beta signaling indirectly through degradation of proteoglycans.

\section{Protein changes in malignant stages of the colon cancer (CC NM and CC M, clusters UII and UDD)}

In addition to matrix acting proteases, proteins increased in the cancer cluster (UII) were associated with inflammation/immune response and antimicrobial activity (neutrophil defensin 1 and 4, fibrinogen alpha, beta and gamma chains, prothrombin, protein S100-A8 and A9, cathepsin E, coiled-coil domain-containing protein $88 \mathrm{~B}$ ), cytoskeletal re-modelling (nesprin-1, fascin, actin-related protein $2 / 3$ complex subunit 4 , allograft inflammatory factor 1, plastin-2, macrophage-capping protein, neurabin-2, calponin-2, twinfilin-1, brain-specific angiogenesis inhibitor 1-associated protein 2, serine/threonine-protein kinase PAK 2) and 15 proteins involved in ubiquitinlinked protein degradation (Fig. 2a). 


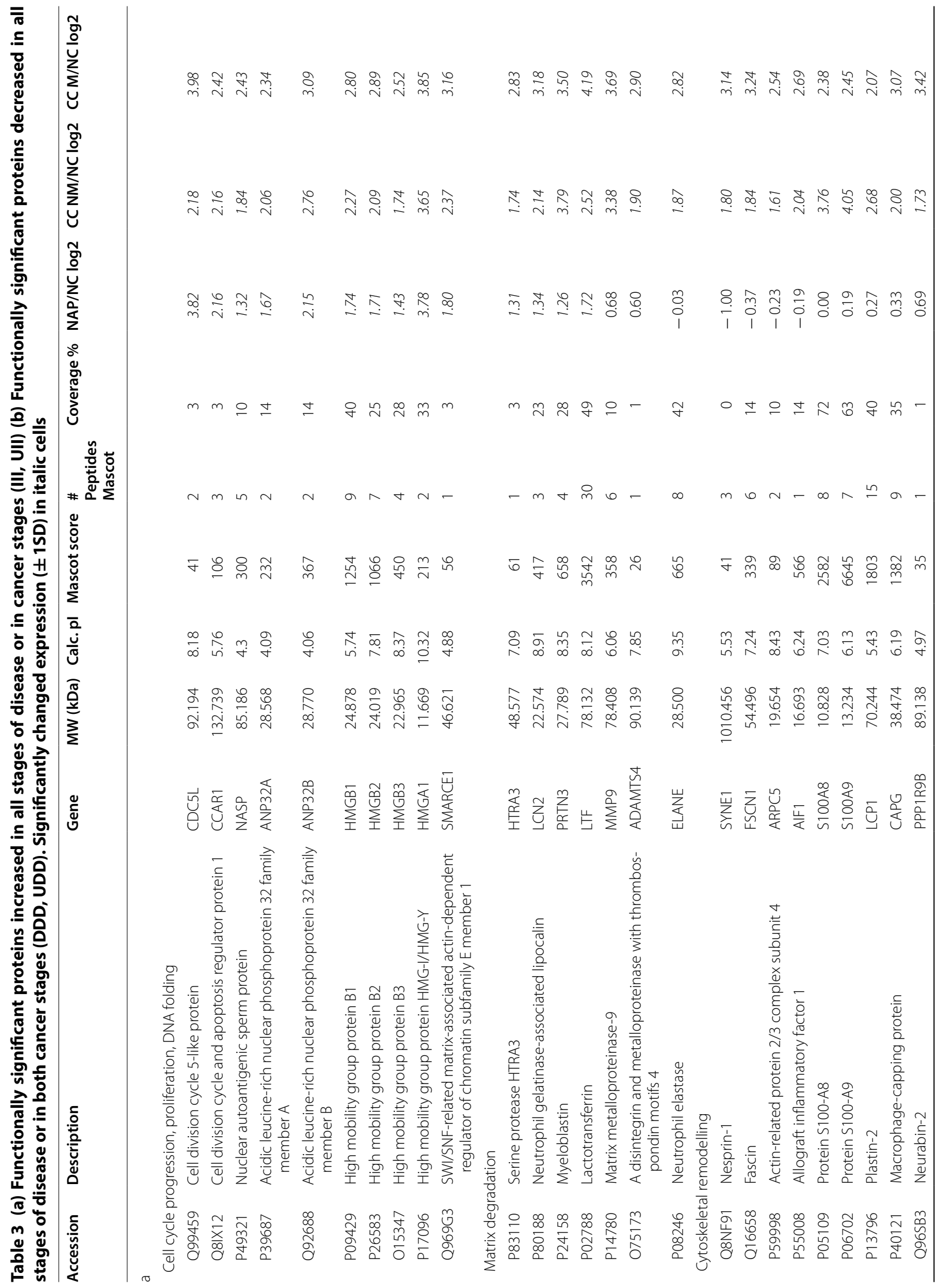




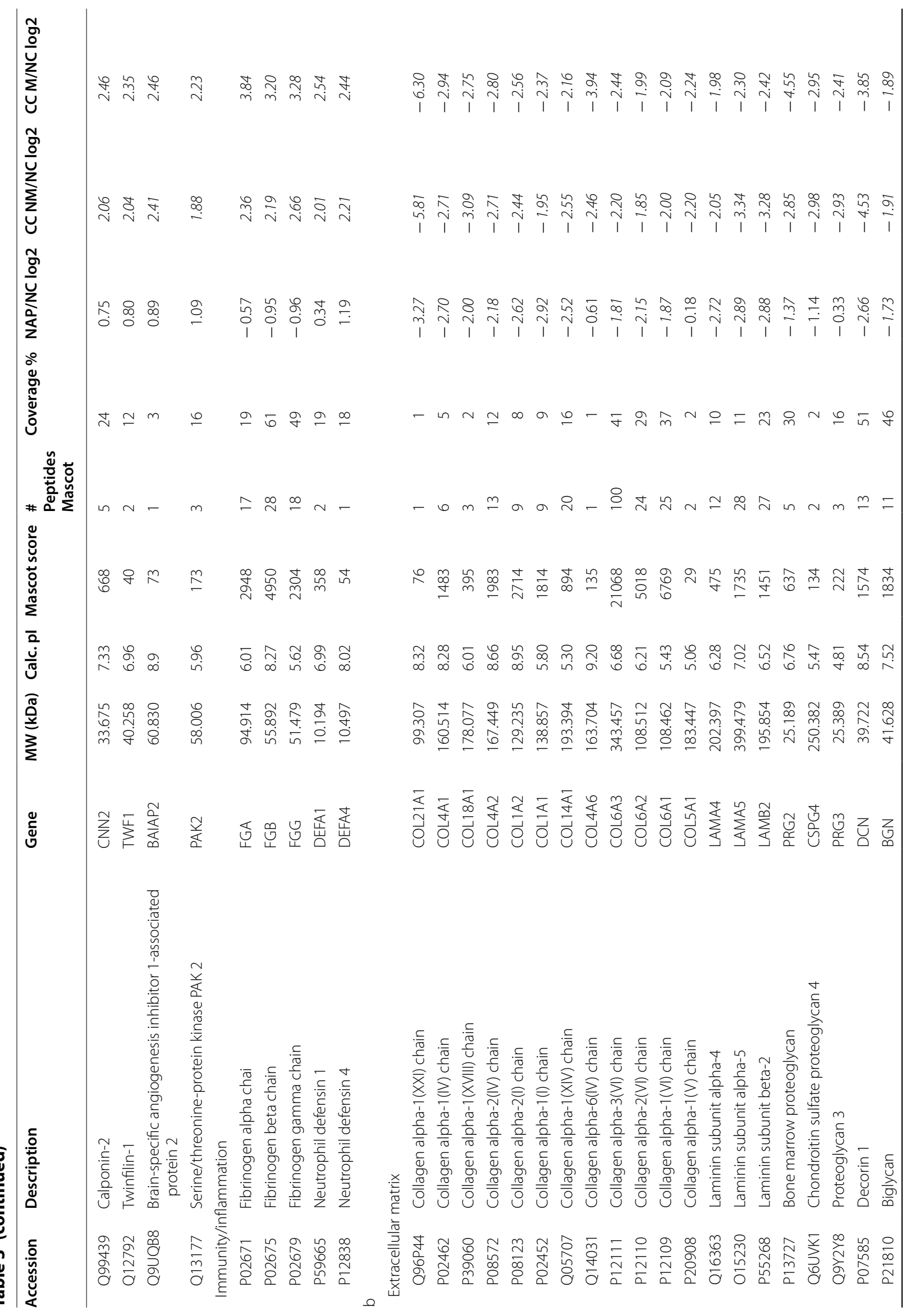




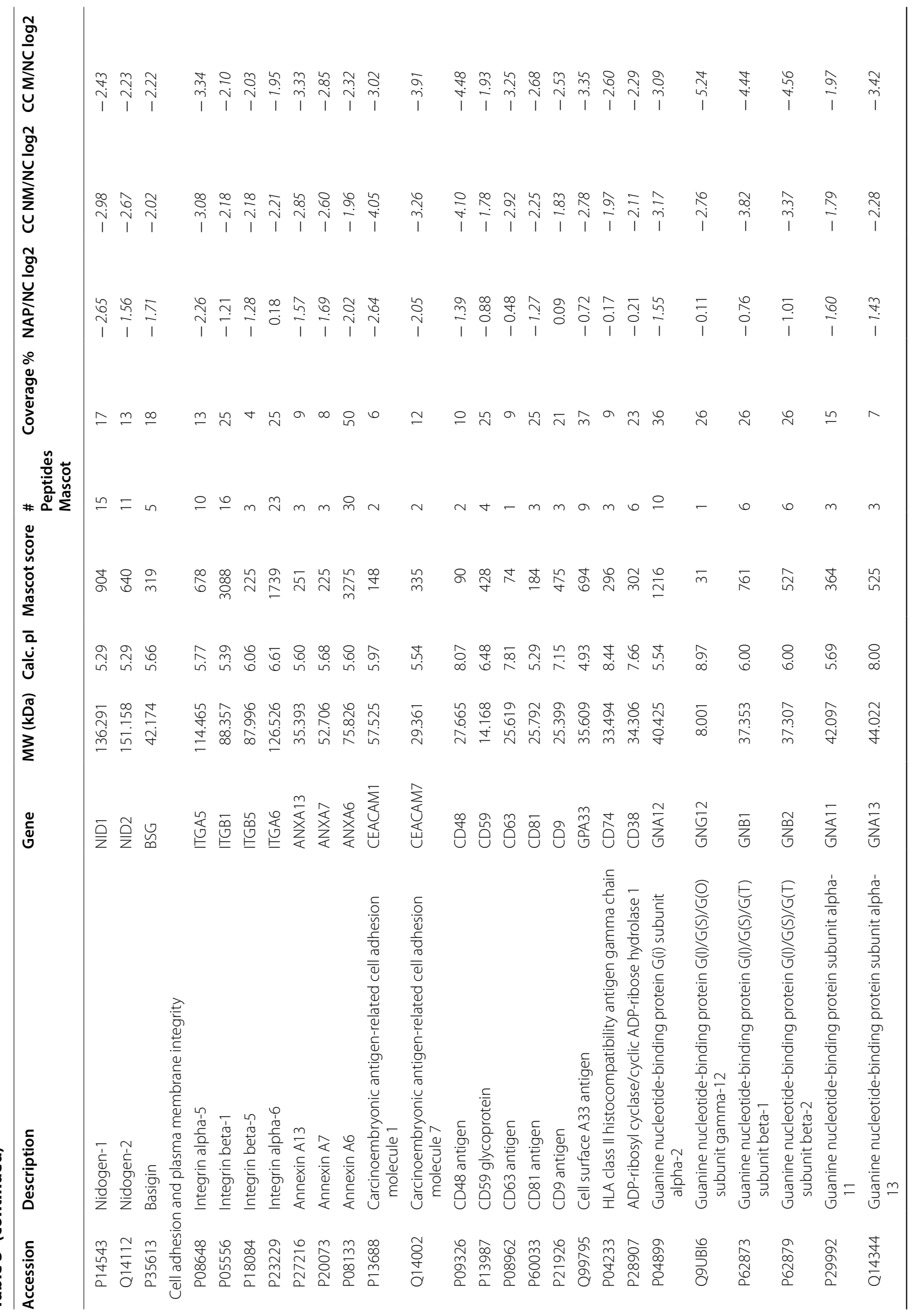




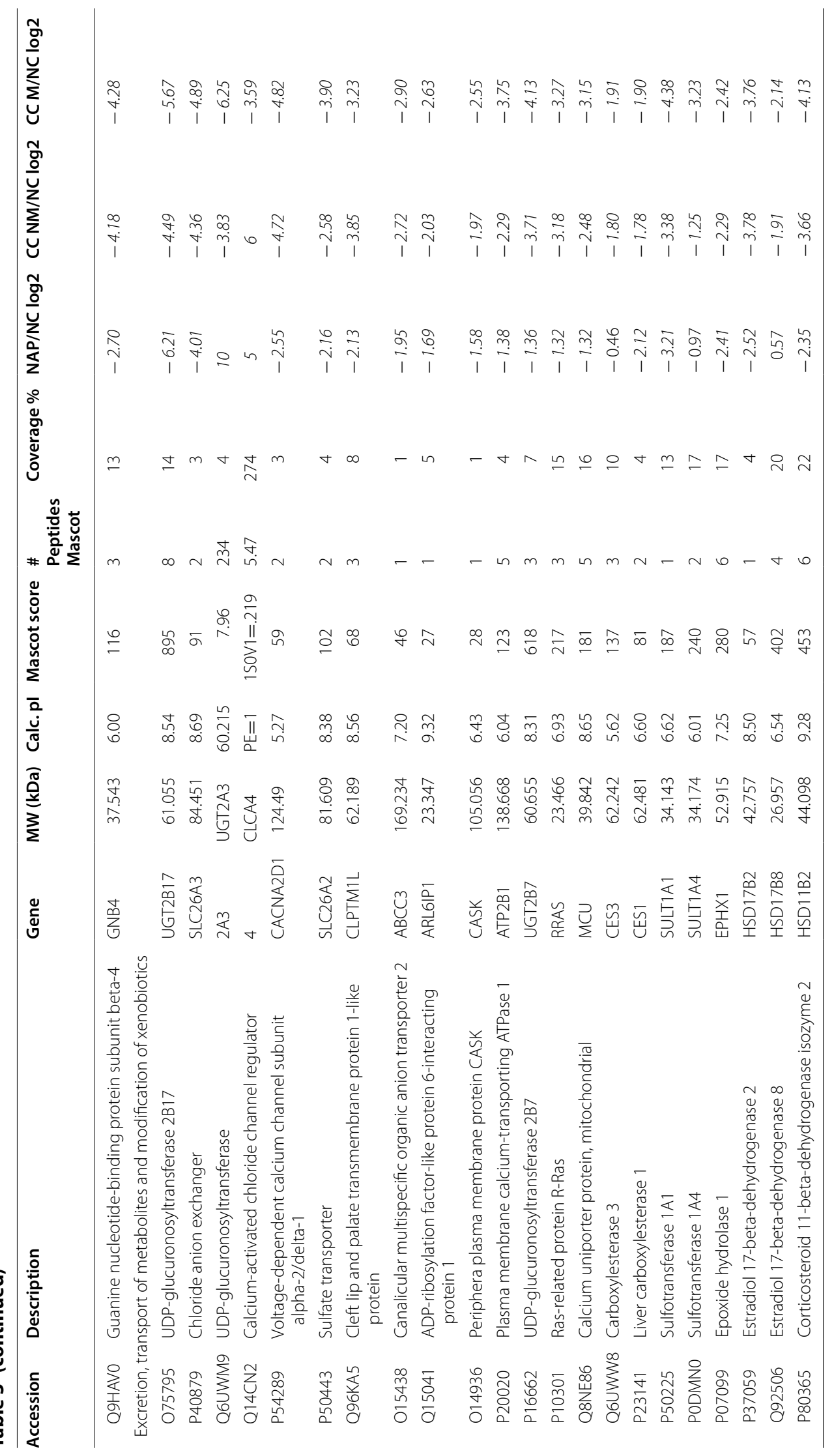




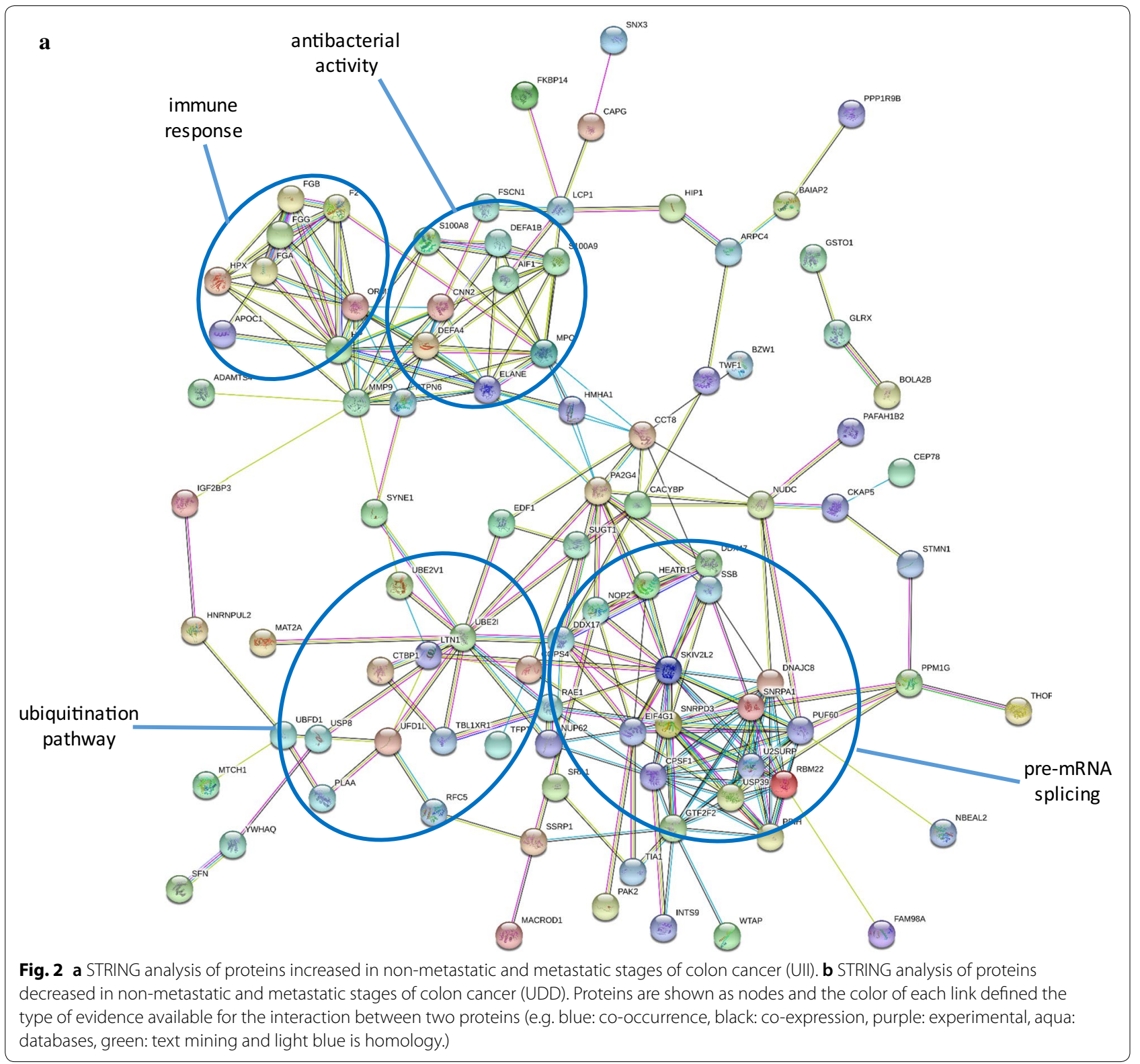

Those proteins that were decreased in cancer stages but not benign (UDD, PPI enrichment $\mathrm{p}<1.0 \mathrm{e}-16$ ), were noticeable associated with mitochondrial function affecting electron transport and the respiratory chain, citric acid cycle, ATP synthase, mitochondrial ribosomes and DNA replication, ADP/ATP transport and other metabolite trafficking (Fig. 2b). Overall this suggests a decrease in mitochondria composition within colon cancer cells $(\mathrm{FDR}=1.67 \mathrm{E}-10)$. Glucagon was also one of the proteins increased in this group. Increased glucagon can result in hepatic gluconeogenesis contributing to metabolic syndrome cancer cachexia [19] leading to negative energy balance [20], weight loss and reduced food intake [21].
Elevated glucagon promotes release of glucose which stimulates tumor protein synthetic rate to double in colorectal cancer [22].

A group of proteins decreased in colon cancer nonmetastatic and metastatic stages were associated with plasma membrane function indicating loss of cell-cell adhesion, cell junctions and cell-matrix interaction which was already in evidence in benign disease in the form of decreased G-protein-linked transmembrane signaling. Isoforms of $\mathrm{G}$ protein alpha, beta and gamma subunits, integrin alpha and beta subunits $\left(\alpha_{1}, \alpha_{3}, \alpha_{5}, \alpha_{7}, \alpha_{x}, \beta_{1}\right.$ and $\left.\beta_{5}\right)$ and annexins (A1, A2, A4, A5, A6, A7, A11 and A13) exhibited a reduction in levels indicating a suppression of membrane 


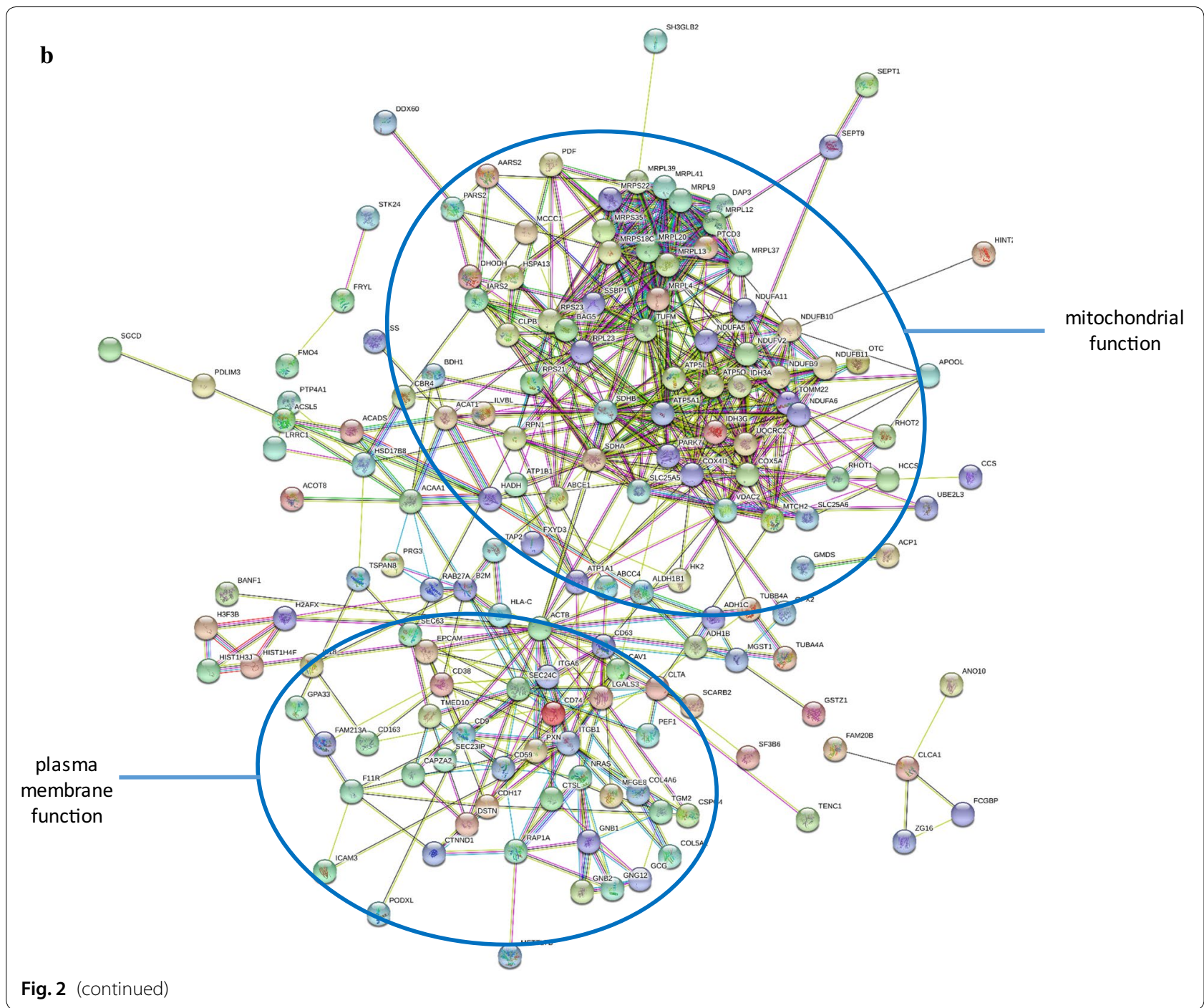

signal transduction (see Table $3 \mathrm{~b}$ ). Integrins are stimulators of cancer cell proliferation and tumor angiogenesis [23] linked to the Ras-ERK pathway by CAV-1, tyrosine kinase Fyn and Shc [24] and integrin alpha-1 expression is directly regulated by oncogenic factor c-MYC [25]. N-Ras and R-Ras were both decreased in our proteomics dataset, along with proteins associated with transport vesicle and caveolae formation, including CAV-1.

\section{Protein changes in later stage of the colon cancer (CC M, clusters UUI and UUD)}

Those protein uniquely increased in tumors that have advanced to a metastatic stage (UUI, 78 proteins), indicating an escalation of immune/inflammation response (complement component $\mathrm{C6}$, factor $\mathrm{H}$, syntenin-1, apoptosis-associated speck-like protein containing a CARD, protein canopy homolog 3) and ubiquitin-associated protein turnover (ubiquitin-conjugating enzyme E2 N, ubiquilin-1, -2 and -4, TP53-binding protein 1 and centrosomal protein of $131 \mathrm{kDa}$ ). Ubiquilin proteins play a role in LC3-mediated production of autophagosomes, a process indicative of the harsh microenvironment of solid tumors starved of oxygen and nutrients, from which select cancer cell may well survive to spread by metastasis (Additional file 3: Figure S1 (iii)) [26].

Those proteins decreased only in late stage colon cancer indicated further losses in mitochondrial function and membrane transport activity (Additional file 3: Figure S1(iv)). In addition, mucin-2, which is a highly abundant component of colon mucus layers was decreased and suggestive of a massive disruption of normal tissue morphology as these advanced tumors invade the surrounding organs. Interestingly, there was an inverse response in the expression of mucin-5AC, which is normally detected in gastric and respiratory tract mucosa. 


\section{Protein signatures specifically related to benign disease (NAP, clusters IUU and DUU)}

Increased protein signatures, uniquely associated with benign disease (non-adenomatous polyps) were strongly coupled with transcriptional (spliceosomal) and translational processing (ribosomal) $(\mathrm{FDR}=8.13 \mathrm{E}-25)$ (Additional file 3: Figure S1(v)). No clear functional profiles was derived from the analysis of the decreased proteins, though many components were linked to neutrophil degranulation $(\mathrm{FDR}=4.01 \mathrm{E}-07)$ (Additional file 3: Figure $\mathrm{S} 1(\mathrm{vi}))$.

\section{Caveolin-1 and MMP-9 expression}

We aimed to validate a protein identified with as low as $\leq 10$ peptides in our ESI-MS data and had already been associated with colon cancer progression. So we selected caveolin-1 (CAV-1) from the cluster C10 (Fig. 1) UDD (unchanged between benign and non-cancer tissues but decreased in both non-metastatic and metastatic and tumor as compared to non-cancer tissues) and Matrix metalloproteinase-9 (MMP-9) from the cluster C18 (Fig. 1) UII (unchanged between benign and non-cancer tissues but increased in both non-metastatic and metastatic and tumor as compared to non-cancer tissues) for further investigation. In so doing we wished to determine if CAV-1 and MMP-9 have the potential to be a suitable biomarker. There is contradictory evidence of the expression changes of CAV-1 in different cancer tissues [27-31], yet clear pivotal role in different oncogenic processes. Although not used diagnostically, the role of MMP-9 has been well described in CRC invasion and metastasis, enabling tumor growth and cancer cells to escape into circulation [32-35].

We screened the expression of these proteins on discrete and unique patient samples ranging from tissues from non-cancer (screening patients) to benign/nonmalignant polyps and poorly- to well-differentiated colon cancer tissues. We intended to analyse our patient population (Asian/Pakistani) and establish CAV-1 and MMP-9 significance in colon cancer. CAV-1, MMP-9 and $\beta$-actin (loading control) were analysed by western blotting of protein extracts from an independent cohort of 86 patients with well characterized normal colon mucosa, benign polyps and tumors from stage I-IV tissues histopathologies (Fig. 3a, Additional file 4: Figure S2). Our results indicate CAV-1 is expressed in all tissue types in various degrees. Normal tissues from non-cancer patients (Fig. 3a: NC, NAP) expressed CAV-1 and MMP-9. The slight increase in expression of CAV-1 in CC NM I T compared to CC NM I $\mathrm{N}$ (Fig. 3a) shows a different response to that determined by proteomics analysis where a decrease in tumor was observed as compared to the non-cancer tissue (UDD).

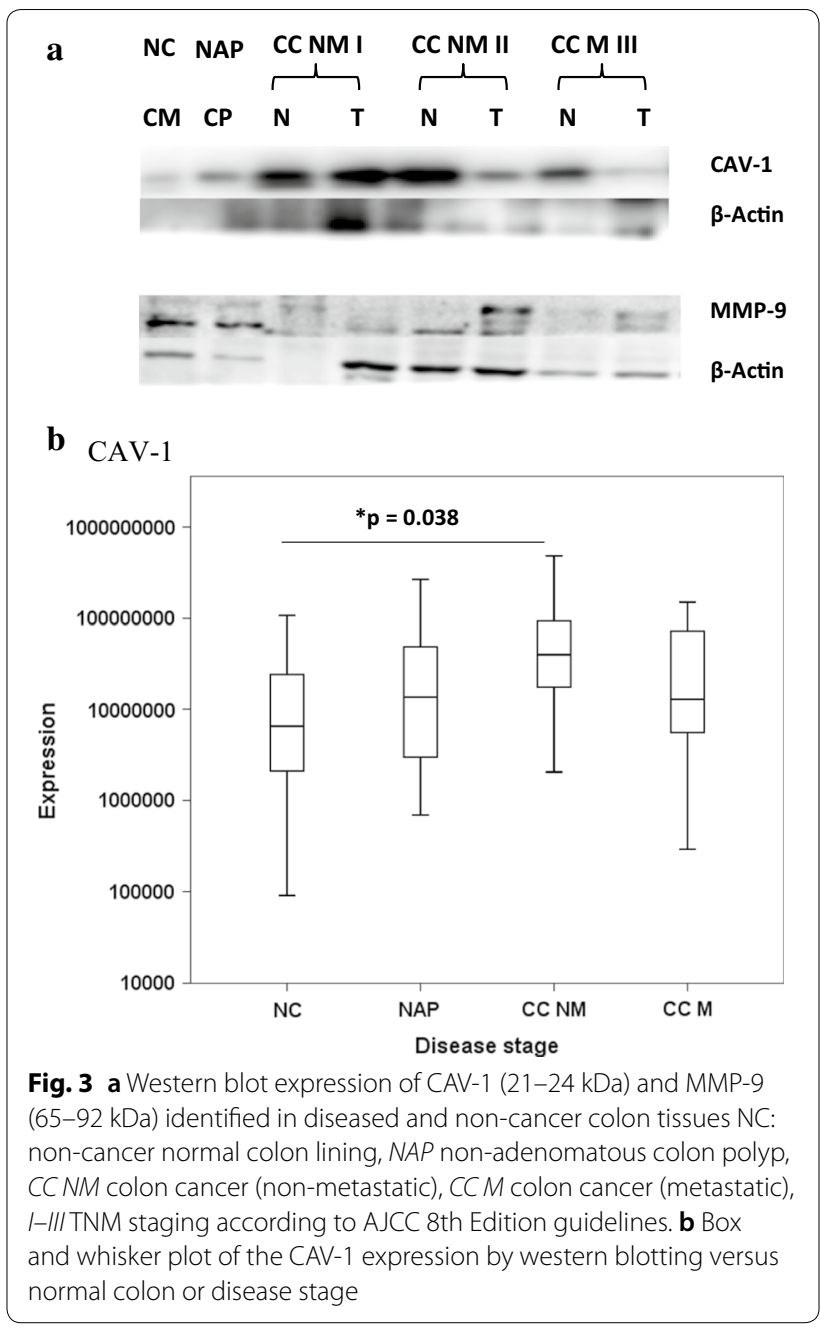

However normal tissues from cancer patients (Fig. 3a: CC NM II N and CC M III N) expressed higher CAV-1 than the matched tumor tissues (Fig. 3a: CC NM II T and CC $\mathrm{M}$ III T). This decrease in CAV-1 expression in tumor tissue suggests that loss of CAV-1 is required for the disease to establish which relates to clinical outcome. Overall the findings of the study reflect patient-to-patient variations. This warrants further investigation to determine if CAV-1 is a biomarker of early colon cancer or an indicator of abnormal growth in colon mucosa. Analysis of the cohort (Fig. 3b, Additional file 5: Table S3a), indicates that the trend of expression of CAV-1 is increasing from $\mathrm{NC}$ to CC NM ( $<<0.038$, Additional file 5: Table S3c), but then decreases in $\mathrm{CC} M$. Similar properties for $\beta$-actin were observed. The MMP-9 (Fig. 3a) shows a similar response to that determined by proteomics analysis where an increase in tumor was observed as compared to the non-cancer tissue (UII). Tumor tissues from cancer patients (Fig. 3a: CC NM II T and CC M III T) expressed higher MMP-9 than the matched normal tissues (Fig. 3a: CC NM II N and CC 
M III N). This increase in MMP-9 expression in tumor tissue suggests that increased expression of MMP-9 is required for the disease to establish or spread. Overall the findings of the study reflect patient-to-patient variations. This warrants further investigation to determine if CAV-1 and MMP-9 are biomarkers of early colon cancer or an indicator of abnormal growth in colon mucosa.

\section{Discussion}

Many of those proteins that were significantly changed in this investigation, have formerly been associated with colon cancer, including HLA class II histocompatibility antigen gamma chain (CD74) [36], carcinoembryonic antigen-related cell adhesion molecule-7 (CEACAM-7) [37], glutathione S-transferase omega-1 (GSTO1) [38], matrix metalloproteinase-9 (MMP-9) [35], hepatoma-derived growth factor (HDGF) [39], lactotransferrin (LTF) [40], cytoskeleton-associated protein 5 (also known as colonic and hepatic tumor overexpressed gene protein) [41] and DNA (cytosine-5)-methyltransferase 1 [42]. CD74 was previously shown to be decreased in cancer samples based on mRNA levels (NAP/NC ratio $\log _{2}-0.169$, CC NM/NC -1.966 and $\mathrm{CC} \mathrm{M} / \mathrm{NC}-2.601$ ) and CEACAM-7 (NAP/ $\mathrm{NC}$ ratio $\log _{2}-2.054, \mathrm{CC} \mathrm{NM} / \mathrm{NC}-3.259$ and $\mathrm{CC} \mathrm{M} /$ $\mathrm{NC}-3.911$ ) based on immunohistochemistry staining. GSTO1 expression was unchanged in non-adenomatous, but significantly elevated in non-metastatic and metastatic states (NAP/NC ratio $\log _{2}-0.022, \mathrm{CC} \mathrm{NM} / \mathrm{NC}$ 1.854 and $\mathrm{CC} \mathrm{M} / \mathrm{NC} 2.452)$. GSTO1 knock-down by the inhibitor $\mathrm{C} 1-27$ in colon cancer cell line HCT116 resulted in down-regulation of Dickkopf-related protein 1 (DKK1), thombospondin 1 (THBSS1) and CAV-1 [43]. MMP-9 (NAP/NC ratio $\log _{2} 0.677, \mathrm{CC} \mathrm{NM} / \mathrm{NC} 3.379$ and CC M/ NC 3.691), which is responsible for extracellular matrix degradation exhibited an even more profound response. Two anti-apoptotic proteins HDGF (NAP/NC ratio $\log _{2}$ 1.349, CC NM/NC 2.237 and CC M/NC 3.244) and LTF (NAP/NC ratio $\log _{2} 1.724, \mathrm{CC}$ NM/NC 2.521 and CC M/ $\mathrm{NC} 4.186)$ were increased in all disease conditions. HDGF is associated with CRC progression with cellular proliferation, migration, invasion, and tumorigenesis noticeably decreased in HCT116 and HT29 in vitro and in vivo HDGF knockdown models [39, 44]. LTF knockout resulted in inflammation-induced colorectal dysplasia in mice probably by inhibition of NF- $\mathrm{kB}$ and AKT/mTOR signaling suggesting a protective role in colorectal inflammation-related malignant transformation [40].

Metabolic functions of mitochondria are instrumental in tumor anabolism, oxidative stress, $\mathrm{Ca}^{2+}$ homeostasis and cell death. [45]. Accumulation of dysfunctional mitochondria generates increased tumor-promoting reactive oxygen species (ROS) and tumorigenic signals [46]. Clearance of dysfunctional mitochondria via mitophagy is critical for cellular fitness [47]. A major trigger for mitochondrial clearance in tumor cells is mitochondrial membrane depolarization and hypoxia, activating PTENinduced putative kinase 1 (PINK1)/Parkin pathway or through Bcl-2 [46]. Elevated mitochondrial fission by dynamin-related protein-1 (Drp1) recruitment leading to impaired cancer cell growth suggests its importance in tumorigenesis [48].

CAV-1 moderates lipid trafficking and is known to be up-regulated in drug resistant cancer cell lines [28] and in colon cancer, histone modifications bring about the genetic drift in CAV-1 gene regulation instead of DNA methylation [49], which agrees with the observations by Western blot analysis. CAV-1 plays an important role in cell migration and is a regulator of the K-RAS oncogene in colon carcinogenesis. It was demonstrated that colon tumor cells harboring K-RAS mutations had higher levels of CAV-1-1 mRNA levels involving the AKT pathway [50]. Paradoxically, decreased expression of CAV-1 has also been indicated as a potential prognostic factor for CRC [31, 51], which correlated with the proteomics results observed in this study with significant decrease from CC NM to CCM, but not NAP (NAP/NC ratio $\log _{2}$ -0.712 , CC NM/NC -2.193 and $\mathrm{CC} \mathrm{M/NC} \mathrm{-2.466).}$ CAVs are structural proteins forming $50-$ to $100-\mathrm{nm}$ invaginations of the plasma membrane called caveolae that function as regulators of signal transduction. CAV-1 levels are positively correlated with tumor stage/grade in a number of cancer types and regulates multiple cancerassociated processes including cellular transformation, tumor growth, cell migration, cell death and survival, multidrug resistance and angiogenesis [52]. CAV-1 gene endogenous expression or re-expression may also reduce pancreatic carcinoma cell invasion probably through Erk-MMP signal pathway [53]. Furthermore, expression of CAV-1 in the ovarian carcinoma cell line OVCAR-3, resulted in suppression of tumor cell survival in vitro, suggesting that the CAV-1 gene is likely to act as a tumorsuppressor gene in human ovarian epithelium [54]. CRC patients with high stromal CAV-1 had a good (92\%) 5 -year survival rate, in contrast to patients with moderate levels or absent CAV-1 [54]. Overall, the complex role of CAV-1 in cancer explains the divergent results we have observed reflecting patient-to-patient variation in oncogenic events. Interestingly, $\beta$-actin was also observed to be decreased in colon proteomics results, whilst Western blotting results indicate a rise with early stage disease. As with CAV-1, there was significant patient variation, which may reflect tissue heterogeneity independent of cancer stage. One of the challenges of the studies using $\beta$-actin as a loading control is that $\beta$-actin is a protein itself and its expression varies from patient-to-patient just as with several other proteins. We reported our 
observations which emphasize the fact that alternate loading control strategies should be followed instead of selecting patient proteins which are all altered in case of the colon cancer disease. We have screened a large number of patients tissues $(n=86)$ using western blotting that shows expression variations in different patients. This study is the first to report CAV-1 expression in nonmalignant and malignant colon-specific tissues both by proteomics and by classical technique. There is evidence from our results that an increase in CAV-1 expression can differentiate non-metastatic cancer from normal, but this requires a more extensive study. Laser capture microdissection to isolate cancer cells would enable clarification of the expression variation in future studies.

\section{Conclusions}

With the incidence of CRC increasing worldwide at an alarming rate, it is important to discover patientspecific panel of prognostic factors and biomarkers for early detection and treatment. Proteomics provides the opportunity to screen changes in different tissues with pathologically altered proteome compared to the normal. Non-malignant and malignant tissues were selected to determine subtle changes at molecular level bringing about major shifts in disease state.

Despite genetic variations, there are proteins which are still common among colon cancer patients. Identifying the pool of differentially expressed proteins can be of meaningful significance in understanding the disease establishment. Our preliminary study has demonstrated the ability to undertake extensive quantitative proteomics analysis of individual small colon cancer biopsies (averaging $5 \mathrm{~mm}^{3}$ ) and gain an understanding of anatomicallyspecific disease progression. A number of proteins were up-regulated or down-regulated through stages of the disease, were associated with well-established characteristics of cancer progression and represent targets for further investigation. An ability to validate a known target in caveolin-1, served only to confirm seemingly contradictory evidence of increase and decrease in CRC that has been reported previously. In this study, we demonstrated that levels were stage-dependent, but also varied significantly from patient-to-patient. Nevertheless, the results have provided scope to explore new solutions in population profiling, such as microarray assays that will generate diagnostics for challenging environments such as those found in developing countries.

\section{Supplementary information}

Supplementary information accompanies this paper at https://doi. org/10.1186/s12014-019-9264-y.
Additional file 1: Table S1. Patient clinicopathological data (a) Patient cohort for proteomics analysis (b) Patient cohort for Western blot analysis.

Additional file 2: Table S2. Complete set of proteins identified by proteomics analysis.

Additional file 3: Figure S1. STRING analysis of major proteins clusters responding to colon cancer progression (i) Increased in all stages (III) (ii) Decreased in all stages (DDD) (iii) Increased only in late metastatic stage (UUI) (iv) Decreased only in late metastatic stage (UUD) (v) Increased only in benign disease (NAP) (IUU) (vi) Decreased only in benign disease (NAP) (DUU).

Additional file 4: Figure S2. Extended studies of CAV-1 and MMP-9 by Western blotting NC: non-cancer normal colon lining, NAP: non-adenomatous colon polyp, CC NM: colon cancer (non-metastatic), CC M: colon cancer (metastatic) E: Endoscopy patient S: Surgery patient.

Additional file 5: Table S3. Calculated band intensities for (a) CAV-1 and (b) $\beta$-actin after background subtraction (c) Student $t$ Test.

\section{Acknowledgements}

We thank Shaukat Khanum Memorial Cancer Hospital and Research Centre, Lahore, Pakistan for funding research of SS and Yorkshire Cancer Research for supporting the research of CS and SuS. Ethical approval was obtained from SKMCH\&RC Internal Review Board and consent forms were signed by patients.

\section{Authors' contributions}

SS contribution: Conception and design of the study, acquisition of data, analysis and interpretation of data, drafting the article, revising it critically for important intellectual content, final approval of the version to be submitted. ST, IA and S contribution: Acquisition of data, analysis and interpretation of data, drafting the article, final approval of the version to be submitted. MT and SH contribution: Acquisition of data, analysis of data, final approval of the version to be submitted. AA contribution: Acquisition of data, analysis and interpretation of data, final approval of the version to be submitted. MAB contribution: Statistical analysis of data, final approval of the version to be submitted. SK, AAS, AHA, MH and MAY contribution: Acquisition of data, analysis and interpretation of data, revising the draft critically for important intellectual content, final approval of the version to be submitted. CS contribution: Design of the study, analysis and interpretation of data, drafting the article, revising it critically for important intellectual content. All authors read and approved the final manuscript.

\section{Funding}

This work was supported by Shaukat Khanum Memorial Cancer hospital and Research Center, Pakistan Chris Sutton and Sadr ul Shaheed work is supported by Yorkshire Cancer Research, UK. They had no involvement in the study design and writing of article.

\section{Availability of data and materials}

We confirm that all the associated data to this study is available and can be produced at request. Most of the data is submitted as supporting material.

\section{Ethics approval and consent to participate}

The ethical approval of the study was obtained from Institutional Review Board (IRB) at Shaukat Khanum Memorial Cancer Hospital and Research Center, Lahore, Pakistan. The IRB/IEC(s) (IORG0004939) of SKMCH\&RC is registered with the Office for Human Research Protections (OHRP) US Department of Health and Human Services. The informed consent of all participating subjects is obtained.

\section{Consent for publication}

We agree for publication upon acceptance and we agree that all copyright ownership for the article is transferred to-Clinical Proteomics (ISSN: 15590275). The material submitted is new, original and has not been submitted to another journal for concurrent consideration.

\section{Competing interests}

The authors declared that they have no competing interests. 


\section{Author details}

${ }^{1}$ Basic Science Research, Shaukat Khanum Memorial Cancer Hospital and Research Centre, 7-A Block R-3, Johar Town, Lahore 54000, Pakistan. ${ }^{2}$ Institute of Cancer Therapeutics, University of Bradford, Tumbling Hill Street, Bradford BD7 1BD, UK. ${ }^{3}$ Department of Pathology, Shaukat Khanum Memorial Cancer Hospital and Research Centre, 7-A Block R-3, Johar Town, Lahore 54000, Pakistan. ${ }^{4}$ Clinical Research Office, Shaukat Khanum Memorial Cancer Hospital and Research Centre, 7-A Block R-3, Johar Town, Lahore 54000, Pakistan. ${ }^{5}$ Cancer Registry and Clinical Data Management, Shaukat Khanum Memorial Cancer Hospital and Research Centre, 7-A Block R-3, Johar Town, Lahore 54000, Pakistan. ${ }^{6}$ Department of Surgical Oncology, Shaukat Khanum Memorial Cancer Hospital and Research Centre, 7-A Block R-3, Johar Town, Lahore 54000, Pakistan. ${ }^{7}$ Department of Internal Medicine, Shaukat Khanum Mmemorial Cancer Hospital and Research Centre, 7-A Block R-3, Johar Town, Lahore 54000, Pakistan.

Received: 12 August 2019 Accepted: 12 December 2019 Published online: 28 December 2019

\section{References}

1. Arnold M, et al. Global patterns and trends in colorectal cancer incidence and mortality. Gut. 2016;66(4):683-91.

2. Ng SC, Wong SH. Colorectal cancer screening in Asia. Br Med Bull. 2013;105:29-42

3. Khan NA, et al. Dietary practices, addictive behavior and bowel habits and risk of early onset colorectal cancer: a case control study. Asian Pac J Cancer Prev. 2015;16(17):7967-73.

4. Huxley $\mathrm{R}$, et al. The role of lifestyle risk factors on mortality from colorectal cancer in populations of the Asia-Pacific region. Asian Pac J Cancer Prev. 2007;8(2):191-8.

5. Bhurgri Y, et al. Pakistan-country profile of cancer and cancer control 1995-2004. J Pak Med Assoc. 2006;56(3):124-30.

6. Akhtar F. Cancer registration in Pakistan: contemporary state of affairs. Asian Pac J Cancer Prev. 2007;8(3):452.

7. Bhurgri Y, et al. Cancer incidence in Karachi, Pakistan: first results from Karachi cancer registry. Int J Cancer. 2000;85(3):325-9.

8. Jamal S, Atique M, Khadim MT. Changing pattern of malignancies: analysis of histopathology based tumour registry data and comparison of three decades at Armed Forces Institute of Pathology, Rawalpindi, Pakistan. J Pak Med Assoc. 2014;64(1):24-7.

9. Anwar N, Badar F, Yusuf MA. Profile of patients with colorectal cancer at a tertiary care cancer hospital in Pakistan. Ann N Y Acad Sci. 2008;1138:199_ 203. https://doi.org/10.1196/annals.1414.026.

10. Badar F, et al. Epidemiology of cancers in Lahore, Pakistan, 2010-2012: a cross-sectional study. BMJ Open. 2016;6(6):e011828.

11. Álvarez-Chaver $P$, et al. Proteomics for discovery of candidate colorectal cancer biomarkers. WJG. 2014;20(14):3804-24.

12. Cristobal A, et al. Personalized proteome profiles of healthy and tumor human colon organoids reveal both individual diversity and basic features of colorectal cancer. Cell Reports. 2017;18(1):263-74.

13. Kreutz $D$, et al. Response profiling using shotgun proteomics enables global metallodrug mechanisms of action to be established. Chemistry. 2017;23(8):1881-90.

14. Wang JJ, et al. Comparative proteomics analysis of colorectal cancer. Asian Pac J Cancer Prev. 2012:13(4):1663-6.

15. Friedman $\mathrm{DB}$, et al. Proteome analysis of human colon cancer by twodimensional difference gel electrophoresis and mass spectrometry. Proteomics. 2004;4(3):793-811.

16. Zhang B, et al. Proteogenomic characterization of human colon and rectal cancer. Nature. 2014;513(7518):382-7.

17. Ngoka LC. Sample prep for proteomics of breast cancer: proteomics and gene ontology reveal dramatic differences in protein solubilization preferences of radioimmunoprecipitation assay and urea lysis buffers. Proteome Sci. 2008:6:30.

18. Towbin H, Staehelin T, Gordon J. Electrophoretic transfer of proteins from polyacrylamide gels to nitrocellulose sheets: procedure and some applications. Proc Natl Acad Sci USA. 1979;76(9):4350-4.
19. Chevalier S, Farsijani S. Cancer cachexia and diabetes: similarities in metabolic alterations and possible treatment. Appl Physiol Nutr Metab. 2014;39(6):643-53.

20. Inui A. Cancer anorexia-cachexia syndrome are neuropeptides the key? Cancer Res. 1999;59(18):4493-501.

21. Porporato PE. Understanding cachexia as a cancer metabolism syndrome Oncogenesis. 2016;5:e200.

22. Hartl WH, et al. Effect of glucagon on protein synthesis in human rectal cancer in situ. Ann Surg. 1998;227(3):390-7.

23. Le Tourneau C, Faivre S, Raymond E. The role of integrins in colorectal cancer. Oncology (Williston Park). 2007;21(9 Suppl 3):21-4.

24. Wary KK, et al. A requirement for caveolin-1 and associated kinase Fyn in integrin signaling and anchorage-dependent cell growth. Cell. 1998;94(5):625-34.

25. Boudjadi S, et al. Integrin [alpha]1[beta]1 expression is controlled by c-MYC in colorectal cancer cells. Oncogene. 2016;35(13):1671-8.

26. McMahon KM, et al. Characterization of changes in the proteome in different regions of 3D multicell tumor spheroids. J Proteome Res. 2012;11(5):2863-75

27. Nunez-Wehinger $\mathrm{S}$, et al. Caveolin-1 in cell migration and metastasis. Curr Mol Med. 2014;14(2):255-74.

28. Shatz M, Liscovitch M. Caveolin-1: a tumor-promoting role in human cancer. Int J Radiat Biol. 2008;84(3):177-89.

29. Quest AF, et al. The caveolin-1 connection to cell death and survival. Curr Mol Med. 2013;13(2):266-81.

30. Zhao Z, et al. Loss of stromal caveolin-1 expression in colorectal cancer predicts poor survival. World J Gastroenterol. 2015;21(4):1140-7.

31. Bender FC, et al. Caveolin-1 levels are down-regulated in human colon tumors, and ectopic expression of caveolin-1 in colon carcinoma cell lines reduces cell tumorigenicity. Cancer Res. 2000;60(20):5870-8.

32. Chu $D$, et al. Matrix metalloproteinase- 9 is associated with relapse and prognosis of patients with colorectal cancer. Ann Surg Oncol. 2012;19(1):318-25.

33. Kostova $\mathrm{E}$, et al. Expression of matrix metalloproteinases 2, 7 and 9 in patients with colorectal cancer. Vojnosanit Pregl. 2014;71(1):52-9.

34. Hurst NG, et al. Elevated serum matrix metalloproteinase 9 (MMP-9) concentration predicts the presence of colorectal neoplasia in symptomatic patients. Br J Cancer. 2007:97(7):971-7.

35. Wilson $\mathrm{S}$, et al. Serum matrix metalloproteinase 9 and colorectal neoplasia: a community-based evaluation of a potential diagnostic test. $\mathrm{Br} \mathrm{J}$ Cancer. 2012;106(8):1431-8.

36. Bozzi F, et al. MIF/CD74 axis is a target for novel therapies in colon carcinomatosis. J Exp Clin Cancer Res. 2017;36(1):16.

37. Messick CA, et al. CEACAM-7: a predictive marker for rectal cancer recurrence. Surgery. 2010;147(5):713-9.

38. Masoudi M, et al. Association between N142D genetic polymorphism of GSTO2 and susceptibility to colorectal cancer. Mol Biol Rep. 2011;38(7):4309-13.

39. Liao F, Dong W, Fan L. Apoptosis of human colorectal carcinoma cells is induced by blocking hepatoma-derived growth factor. Med Oncol. 2010;27(4):1219-26.

40. Ye $\mathrm{Q}$, et al. Lactoferrin deficiency promotes colitis-associated colorectal dysplasia in mice. PLoS ONE. 2014;9(7):e103298.

41. Charrasse $S$, et al. Characterization of the cDNA and pattern of expression of a new gene over-expressed in human hepatomas and colonic tumors. Eur J Biochem. 1995;234(2):406-13.

42. Honeywell RJ, et al. DNA methyltransferases expression in normal tissues and various human cancer cell lines, xenografts and tumors. Nucleosides Nucleotides Nucleic Acids. 2018;37(12):696-708.

43. Ramkumar K, et al. Mechanistic evaluation and transcriptional signature of a glutathione S-transferase omega 1 inhibitor. Nat Commun. 2016;7:13084

44. Lian J, et al. Positive feedback loop of hepatoma-derived growth factor and beta-catenin promotes carcinogenesis of colorectal cancer. Oncotarget. 2015;6(30):29357-74

45. Porporato PE, et al. Mitochondrial metabolism and cancer. Cell Res. 2017;28:265.

46. Vyas S, Zaganjor E, Haigis MC. Mitochondria and cancer. Cell. 2016;166(3):555-66. 
47. Mancias JD, Kimmelman AC. Mechanisms of selective autophagy in normal physiology and cancer. J Mol Biol. 2016;428(9):1659-80.

48. Mishra P, Chan DC. Metabolic regulation of mitochondrial dynamics. J Cell Biol. 2016;212(4):379-87.

49. Deb $M$, et al. Epigenetic drift towards histone modifications regulates CAV1 gene expression in colon cancer. Gene. 2016;581(1):75-84.

50. Basu Roy UK, et al. Caveolin-1 is a novel regulator of K-RAS-dependent migration in colon carcinogenesis. Int J Cancer. 2013;133(1):43-57.

51. Zhao Z, et al. Loss of stromal caveolin-1 expression in colorectal cancer predicts poor survival. WJG. 2015;21(4):1140-7.

52. Nohata $\mathrm{N}$, et al. Caveolin-1 mediates tumor cell migration and invasion and its regulation by miR-133a in head and neck squamous cell carcinoma. Int J Oncol. 2011;38(1):209-17.
53. Han F, Zhu H-G. Caveolin-1 regulating the invasion and expression of matrix metalloproteinase (MMPs) in pancreatic carcinoma cells. J Surg Res. 2010;159(1):443-50.

54. Wiechen $\mathrm{K}$, et al. Caveolin-1 is down-regulated in human ovarian carcinoma and acts as a candidate tumor suppressor gene. Am J Pathol. 2001;159(5):1635-43.

\section{Publisher's Note}

Springer Nature remains neutral with regard to jurisdictional claims in published maps and institutional affiliations.
Ready to submit your research? Choose BMC and benefit from:

- fast, convenient online submission

- thorough peer review by experienced researchers in your field

- rapid publication on acceptance

- support for research data, including large and complex data types

- gold Open Access which fosters wider collaboration and increased citations

- maximum visibility for your research: over $100 \mathrm{M}$ website views per year

At BMC, research is always in progress.

Learn more biomedcentral.com/submissions 